Editorial

\title{
Facilitating Circular Economy in Urban Planning
}

\author{
Hilde Rem $\varnothing y^{1, *}$, Alexander Wandl ${ }^{2}$, Denis Ceric ${ }^{3}$ and Arjan van Timmeren ${ }^{2}$ \\ ${ }^{1}$ Department of Management in the Built Environment, Faculty of Architecture and the Built Environment, Delft University \\ of Technology, 2628 BL Delft, The Netherlands; E-Mail: h.t.remoy@tudelft.nl \\ 2 Department of Urbanism, Faculty of Architecture, Delft University of Technology, 2628 BL Delft, The Netherlands; \\ E-Mails: a.wandl@tudelft.nl (A.W.), a.vantimmeren@tudelft.nl (A.v.T.) \\ ${ }^{3}$ Institute of Geography and Spatial Organization, Polish Academy of Sciences, 00-818 Warszawa, Poland; \\ E-Mail: denis.ceric1@gmail.com
}

* Corresponding author

Submitted: 24 September 2019 | Published: 27 September 2019

\begin{abstract}
A shift towards a more Circular Economy is crucial to achieve a more sustainable and inclusive built environment that meets future demands. Circular Economy is a promising concept for industry and society. If implemented well, Circular Economy can deliver environmental benefits and economic advantages for which innovation is essential. To achieve a resource-efficient built environment the Circular Economy should be developed and implemented systemically and on a large scale, going beyond cities. To realise this, local authorities, citizens, and other stakeholders need a collaborative and science-informed decision environment that allows for developing different waste and resource management options, and assessing their impacts on the environment, resilience, spatial quality and quality of life. The articles in this special issue all discuss different aspects of research to deliver solutions and strategies for a circular economy in urban planning throughout Europe, focusing on peri-urban locations. The first article introduces Living Labs as a methodology to co-create circular solutions and strategies with local stakeholders. The second article focuses on governance for the shift towards a Circular Economy, unravelling hindrances and revealing objectives, whereas the third article develops a means to transfer circular strategies and solutions from one location to another. The fourth article presents an open-source tool based on the geodesign approach which links the co-creation of design proposals to impact simulations informed by geographic contexts, systems thinking, and digital technology - the Geodesign Decision Support Environment. Finally, the fifth article presents the first results of incorporating the concept of Circular Economy in an integrative manner in urban design and planning courses.
\end{abstract}

\section{Keywords}

circular economy; circular metabolism; geo decision support environment; knowledge transfer; new ways of governance; peri-urban living labs; resource management; urban metabolism; waste management; wastescapes

\section{Issue}

This editorial is part of the issue "Facilitating Circular Economy in Urban Planning", edited by Hilde Remoy (Delft University of Technology, The Netherlands), Alexander Wandl (Delft University of Technology, The Netherlands) and Denis Ceric (Polish Academy of Sciences, Poland).

(C) 2019 by the authors; licensee Cogitatio (Lisbon, Portugal). This article is licensed under a Creative Commons Attribution 4.0 International License (CC BY).

\section{Introduction}

To meet future demands within a desired sustainable development we need change; a shift from a linear 'take-make-waste' mentality, or the act of converting renewable resources into waste faster than waste can be turned back into resources, to a Circular Economy. The Circular Economy approach introduced by the Ellen MacArthur Foundation, over a decade ago, is widely accepted and taken as a starting point: on the one hand with cascading (re)use within a technical context, and cascading (re)use within a natural systems' context on 
the other. Awareness around Circular Economy is increasing and many countries in the world put Circular Economy on their agenda. It is a promising concept, for industry and society, as well as in policy developments. If implemented well, Circular Economy cannot only deliver key environmental benefits (e.g., reduced resource extraction, limited landfill, minimal pollution), but at the same time results in economic advantages (less dependence on decreasing stock of natural resources, new business opportunities, job creation) for which innovation is essential. Focusing on Europe, a resource-efficient Europe can only be achieved if the Circular Economy is developed and implemented in a systemic way and on a large scale, which goes beyond cities. To realise this, metropolitan and regional circular design solutions are needed. Currently there are few answers to Circular Economy related questions that arise, and the frameworks presently governing metropolitan solutions are not at all times capable of ensuring accountability. As the pervasiveness, complexity, and scale of these systems grows, the lack of meaningful (integrated) metropolitan solutions, which are tested, accountable and thus able to be implemented rapidly-including basic safeguards of responsibility, liability, and due process-is an increasingly urgent concern.

Effective implementation requires a policy mix that optimises synergies and addresses trade-offs between different areas and policies. Thus, local authorities, citizens, and other stakeholders need a collaborative and science-informed decision environment that allows for developing different waste and resource management options, while assessing their impacts on environmental effects, resilience, spatial quality and therewith supporting quality of life in general.

Transitioning towards a Circular Economy requires to work with and in complex systems. For decision-makers, it is crucial to understand the relationships between socio-economic and environmental dynamics and the built environment. Several aspects are crucial for this innovation to take place:

- Establishing a co-creation process that goes beyond individual projects or products and across scales and value chains;

- Understanding the spatial impact of the actual linear economy on the quality of land and soil;

- Different governance approaches;

- Ways of learning between cities and regions that go beyond the simplistic concept of good or best practice but incorporates cultural and spatial specificities;

- Further development of spatial decision environments that include spatial development and industrial ecology aspects and finally;

- The way we educate urban planners and designers, enabling them to include aspects of material flows and resources in their daily practice.
This thematic issue aims to bring together articles on this necessary wide array of attention related to Circular Economy. While touching upon different aspects of supporting the transition towards a Circular Economy on a regional scale, improving wastescapes and managing resource flows in relation to spatial development challenges will be the main focus. This thematic issue presents research that is conducted for the EU Horizon 2020 research REPAiR-REsource Management in Peri-urban Areas: Going Beyond Urban Metabolism. The authors are contributors to the project, working on the project's different aspects, or are involved in the education related to the project.

\section{The Contributions}

\subsection{Integrating Wastescape as a Spatial Element into the Living Labs Approach}

Resource consumption and related waste production are rapidly increasing all over the world, and urban areas account for around $50 \%$ of global solid waste generation. This leads to social and environmental challenges, but also to the production of 'wastescapes'. Peri-urban areas-in-between urban and rural territories-are particularly vulnerable and prone to develop into wastescapes, because they are in general fragmented, low-density, often crossed by large infrastructure networks, and often selected as locations for waste management plants. Hence, they are crossed by waste flows of different natures. A circular approach can positively affect the spatial, social and environmental performances of peri-urban areas. However, the transition towards the Circular Economy has many challenges.

Amenta et al. (2019), in "Managing the Transition towards Circular Metabolism: Living 6 Labs as CoCreation Approach", outline an approach to address these challenges, presenting a co-creation process among researchers, experts and stakeholders in Living Labs (LLs). In the LLs, public-private-people partnerships are developed by applying an iterative methodology consisting of five phases: Co-Exploring, Co-Design, Co-Production, Co-Decision, and Co-Governance. Two LLs, in the Metropolitan Areas of Naples (Italy) and Amsterdam (The Netherlands), are analysed here to illustrate this approach.

\subsection{Understanding the Hinderances for Urban Regions in Their Aim of Shifting to Circular Economy}

In the last decade, the European Union has supported numerous initiatives aiming at reducing waste generation by promoting shifts towards Circular Economy approaches. Governing this process has become imperative. Obersteg et al. (2019), in their article "Urban Regions Shifting to Circular Economy: Understanding Challenges for New Ways of Governance", focus on the 
results of a governance analysis of six urban regions in Europe. By means of semi-structured interviews, document analysis and workshops with local stakeholders, for each urban area a list of governance challenges which hinder the necessary shift to circularity was drafted. In order to compare the six cases, the various challenges have been categorised using the PESTEL-O method. Results highlight a significant variation in policy contexts and the need for these to evolve by adapting stakeholders' and policy-makers' engagement and diffusing knowledge on the Circular Economy. Common challenges among the six regions include a lack of an integrated guiding framework, both political and legal, limited awareness among citizens, and technological barriers. All these elements call for a multi-faceted governance approachable to embrace the complexity of the processes and comprehensively address the various challenges to completing the shift towards circularity in cities.

\subsection{Learning from Each Other: The Difficulties of the Transfer of Circular Economy Solutions}

'Learning from abroad' is a widely recognised and used means to innovate and improve strategies and policies implemented by regions and cities. However, literature on knowledge transfer and related concepts, such as policy transfer, policy mobility or lesson-drawing, does highlight the limitations of this process, especially when it entails simple transfer of (best) practices from 'place $A$ ' to 'place $B$ '. Such a transfer may lead to suboptimal solutions particularly when the imported practices concern complex phenomena, entailing networks of multiple actors and relying on place-specific dynamics. Departing from this critique, the article sheds light on the process of knowledge transfer in the field of a Circular Economy, taking place between the two metropolitan regions of Amsterdam and Naples. This process is guided by an innovative methodology based on a network of LLs generating eco-innovative solutions for using material waste and wastescapes as a resource in peri-urban areas. Using participant observation in knowledge transfer workshops, stakeholder interviews and surveys, Dąbrowski, Varjú and Amenta (2019), in their article "Transferring Circular Economy Solutions across Differentiated Territories: Understanding and Overcoming the Barriers for Knowledge Transfer", investigate how the process of co-creation of knowledge in the relational space of the networked LLs takes place thanks to participation of stakeholders from both regions. This, in turn, allows for concluding what barriers are encountered in such knowledge transfer, what makes solutions transferable across different contexts, and, finally, how the solutions are adapted as they travel from one place to another.

While the first three articles of the thematic issue have a more mono-disciplinary approach, the remaining two articles show the integration of all aspects into urban planning practice and education.

\subsection{A Geodesign Decision Support Environment to Facilitate Decision Making in the Transition towards a Circular Economy}

Improving waste and resource management entails working on interrelations between different material flows, locations and groups of actors. This calls for new decision support tools for validating and translating the complex information on material flows into accessible knowledge usable by the stakeholders in the spatial planning process. By Arciniegas et al. (2019), article "A Geodesign Decision Support Environment for Integrating Management of Resource Flows in Spatial Planning" describes an open-source tool based on the geodesign approach which links the co-creation of design proposals together with stakeholders and impact simulations informed by geographic contexts, systems thinking, and digital technology - the Geodesign Decision Support Environment (GDSE). Though already used for strategic spatial planning, the potential of geodesign for waste management and recycling is yet to be explored. The article draws on empirical evidence from the pioneering application of the tool to promote spatially explicit Circular Economy strategies in the Amsterdam Metropolitan Area.

\subsection{The Circular Economy Concept in Design Education}

The concept of Circular Economy is high on the agenda of many planning agencies in European countries. It has also become a prominent issue in European academic education institutions. It is expected that spatial planning and design can support and add value to the spatial quality dimension of such a transition towards a Circular Economy. However, incorporating the concept of Circular Economy in an integrative manner in urban design and planning courses is challenging because of its metabolic and complex nature. The article "The Circular Economy Concept in Design Education: Enhancing Understanding and Innovation by Means of Situated Learning", by Wandl et al. (2019), presents the first results of integrating design teaching activities at a Faculty of Architecture with an H2O2O financed research project. The integration of research and design education provided the students with a situated and indeed transdisciplinary learning environment. Students rather early in the design process understood that they need to address challenges from a systemic perspective, meaning to understand what are the relationships between different subsystems and their spatial structures. Furthermore, the experiment provided evidence that the eco-innovative solutions developed by the students are seen as an effective option to achieve objectives for a transition towards a Circular Economy by stakeholders.

\section{Acknowledgments}

This issue is based on the EU Horizon 2020 research REPAiR-REsource Management in Peri-urban Areas: 
Going Beyond Urban Metabolism. This project has received funding from the European Union's Horizon 2020 research and innovation programme under Grant Agreement No. 688920.

\section{Conflict of Interests}

The authors declare no conflict of interests.

\section{References}

Amenta, L., Attademo, A., Remøy, H., Berruti, G., Cerreta, M., Formato, E., . . Russo, M. (2019). Managing the transition towards circular metabolism: Living labs as a co-creation approach. Urban Planning , 4(3), 5-18.

Arciniegas, G., Šileryté, R., Dąbrowski, M., Wandl, A., Dukai, B., Bohnet, M., \& Gutsche, J.-M. (2019). A geodesign decision support environment for integrat- ing management of resource flows in spatial planning. Urban Planning, 4(3), 32-51.

Dąbrowski, M., Varjú, V., \& Amenta, L. (2019). Transferring circular economy solutions across differentiated territories: Understanding and overcoming the barriers for knowledge transfer. Urban Planning, 4(3), 52-62.

Obersteg, A., Arlati, A., Acke, A., Berruti, G., Czapiewski, K., Dąbrowski, M., . . . Knieling, J. (2019). Urban regions shifting to circular economy: Understanding challenges for new ways of governance. Urban Planning, 4(3), 19-31.

Wandl, A., Balz, V., Qu, L., Furlan, C., Arciniegas, G., \& Hackauf, U. (2019). The circular economy concept in design education: Enhancing understanding and innovation by means of situated learning. Urban Planning, 4(3), 63-75.

\section{About the Authors}
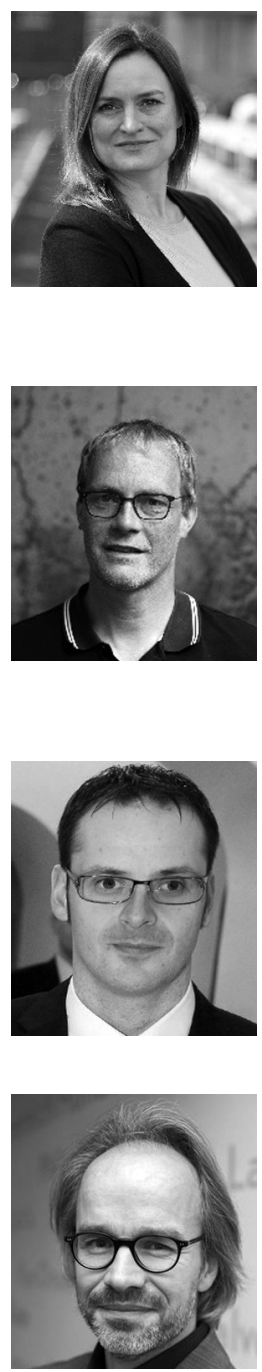

Hilde Remøy is Associate Professor of Real Estate Management at the department of Management in the Built Environment (MBE), Faculty of Architecture and the Built Environment at Delft University of Technology (TU Delft). After an educational and professional path in Norway, Italy, and the Netherlands, she is now teaching, researching and writing on office obsolescence, sustainable building adaptation and adaptive reuse management. In her work, she focuses on sustainability, resilience, lifespan and continued reuse of real estate. Her research ranges from large scale European funded projects to research for Dutch practice, working with researchers and professionals of various disciplines and backgrounds.

Alexander Wandl (MSc) is an Urbanist and Senior Researcher of Environmental Technology and Design, at the Faculty of Architecture and the Built Environment. His research focuses on developing sustainable urbanisation, using an extended territorial metabolism approach and integrating (GIS-supported) methods and tools from different disciplines. As scientific coordinator of the Horizon 2020 Funded Research Project Repair-Resource Management in Peri-Urban Areas-he is at the forefront of developing spatial strategies which support the transition towards more circularity. He specifically focuses on the challenges related to the sustainable development of dispersed urban areas and periurbanisation processes in Europe.

Denis Cerić is an Assistant and a PhD student of human geography at the Institute of Geography and Spatial Organization, Polish Academy of Sciences, with a broad research interest in tourism geography, cruise tourism, cross-border tourism, tourist flows, tourist attractiveness, issues related to spatial planning, organization and regional development of tourism.

Arjan van Timmeren (The Netherlands, 1969) is Full Professor at Delft University of Technology (TU Delft), Faculty of Architecture and the Built Environment, Department of Urbanism, chair 'Environmental Technology \& Design'. He is also Scientific Director of the joint initiative by TUD (Delft), MIT (Boston) and WUR (Wageningen) 'AMS Institute' (Institute for 'Advanced Metropolitan Solutions'), located in Amsterdam. Over the years his work has focused on the integration of the concept of sustainable development in the field of architecture, urbanism and building technology in both practice and academia, with lately emphasis on Urban Metabolism, Circular Economy, Green-Blue systems and Resilience. He is member of several international advisory and steering groups as well as quality teams and scientific committees and leads multiple large research projects in Europe and abroad. His latest book and platform launched is Under Pressure: Water and the City (please check https://underpressure.online) 